\title{
Bibliotecas y libros en la Roma del emperador Calígula
}

\section{Books and libraries at ancient Rome during emperor Caligula}

\author{
José Antonio Rodríguez Valcarcel*
}

\begin{abstract}
RESUMEN ABSTRACT
Este artículo trata de mostrar diversos aspectos de la política cultural en este ámbito por parte de este emperador.

PALABRAS CLAVE: Bibliotecas públicas, libros, bibliopolae, Roma, Calígula.

This article tries to show some aspects of cultural politics in this matter at the Caligula's time.

KEYWORDS:

Public libraries, books, bibliopolae, Rome, Caligula.
\end{abstract}

\section{BIBLIOTECAS}

Tras la intensa y febril actividad constructiva de Augusto en todos los órdenes, no parece que sus inmediatos sucesores Tiberio y Calígula la continuaran con la misma energía, sobre todo el primero, puesto que Cayo, dado su corto gobierno al frente del imperio, no tuvo demasiado tiempo para desarrollar todos los proyectos que las fuentes le asignan en los más diversos órdenes ${ }^{1}$. Entre las construcciones que Suetonio menciona ${ }^{2}$ como pertenecientes a este emperador no se encuentra, al parecer ninguna biblioteca pública: iniciación de un acueducto y un anfiteatro en

* Ministerio de Educación, Política Social y Deporte. C/ Alcalá, 34- 28071 MADRID.

xjoseanx"hotmail. com.

1 Thorton, M.K.: «Julio-Claudian building programs: eat, drink and be merry», Historia, 35 (1986), pp.28-44. "The Julio-Claudian had of course, to construct temples, basilicas and monuments, new dynasties need such psichological proof of power, even more important they had to meet the city's phisical needs (...)», "Tiberius himself consumed most of his public works effort in building his own private house», p. 36; Brunt, P.A.: «Free labour and public works at Rome», Journal of Roman Studies, 70 (1980), pp.81-98.

2 Suetonio, Calígula, 21. 
la región de Tíbur, reconstrucción en Siracusa de las murallas de la ciudad y los templos de los dioses. Como proyectos menciona la reconstrucción en Samos del palacio de Polícrates, la terminación en Mileto del Templo de Apolo Didemeo, la fundación de una ciudad en la cumbre de los Alpes, la cual probablemente hubiera sido un cruce de vías de comunicación estratégicamente muy importante y la perforación del itsmo de Acaya. Ya en Roma podemos citar la finalización del templo de Augusto y del teatro de Pompeyo, obras en el propio palacio, prolongando un área del mismo hacia el foro, de modo que transformó el templo de Castor y Polux ${ }^{3}$ en el vestíbulo de aquél, así como la construcción de un puente que pasaba por encima del templo de Augusto y unía el palacio con el Capitolio. En esta zona estableció los cimientos de un nuevo palacio ${ }^{4} \mathrm{y}$, además, sigue enumerando Suetonio, construyó otros palacios y villas de recreo ${ }^{5}$. Si hemos anotado que en la lista no figura ninguna biblioteca quizá podemos tener una excepción muy clara con el templo de Augusto el cual contenía una, aunque quizá es atribuible totalmente a Tiberio el haber casi concluído el edificio y los servicios que albergaba $^{6}$, dada la rapidez con la que Cayo pudo dedicar el templo. Por otro lado, posiblemente en su palacio y en sus villas dispusiera de pequeñas bibliotecas, como parecen mostrar las excavaciones ${ }^{7}$. Sabemos por Plinio y por Séneca que era común en las grandes casas la existencia de este tipo de bibliotecas particulares así como que era el resultado, en muchas ocasiones, de un afán desmedido por la compra de libros. Plinio en su villa de Laurentes ${ }^{8}$ describe el lugar que ocupaba la biblioteca: "Adnectitur angulo cubiculum in hapsida curvatum, quod ambitum solis fenestris omnibus sequitur. Parieti eius in bybliothecae speciem armarium insertum est, quod non legendos libros sed lectitandos capit». Plinio incluso llegó a donar una biblioteca a su localidad natal ${ }^{9}$. Séneca, por otra parte, criticaba con acidez la moda de comprar libros e instalar bibliotecas en las casas: «(...) iam enim, inter balnearia et thermas, bibliotheca quoque ut necessarium domus ornamentum expolitur. Ignoscerem plane, si studiorum nimia cupidine erra-

${ }^{3}$ Suetonio, Calígula, 22.2; Paterson, J.R.: «The city of Rome: From republic to empire», Journal of Roman Studies, 82 (1992), pp. 186-215. «(...) Hurst's excavations in the Domitianic buildings later occupied by the church of Santa Maria Antiqua have revealed a massive atrium datable by pottery deposits not earlier A.D. 25-30, wich is interpreted as forming part of Caligula's palace», p. 206.

${ }^{4}$ Suetonio, Caligula, 22.4. «Mox, quo propior esset, in area Capitolina nouae domus fundamente iecit». Van Deman, E.B.: «The house of Caligula», American Journal of Archaelogy, 28 (1924), pp. 368-398.

${ }_{5}$ Suetonio, Calígula, 37.2-3; McKay, A.G.: Houses, villas and palaces in the Roman World, Southampton, 1977; Macmullen, R.: Two notes on imperial properties», Athenaeum, 54 (1976), pp. 19-36. Escribe este autor que «Particularly characteristic of the emperor's patrimonium were their great domus and villae, urban, suburban and rural mansions.».

${ }^{6}$ Suetonio, Tiberio, 74, «(...) ut in bibliotheca templi novi poneretur»; Plinio, Naturalis Historia, 34.43 «(...) videmus (...) Tuscanicum Apollinem in bibliotheca templi Augusti»».

7 Casson, L.: Libraries in the Ancient World, New Haven-London, 2001. Describiendo la biblioteca del Palatino dice: «(...) along the side walls were niches measuring 3,80 in heigth, 1,80 in width, and 0,60 in depth. (...) The niches were for the books: fitted into them (...) would have been wooden bookcases- armaria (...)- lined with shelves and closed by doors.», p. 82; e igualmente Van Deman, p. 382, describe un nicho en las paredes de la parte del palacio atribuible al tiempo de Calígula que tiene 1,65 de ancho, una altura indeterminada y una profundidad de entre 50 y 55 centímetros.

8 Plinio, Cartas, 17.8.

9 Lo menciona en una carta a Pompeyo Saturnino. Libro I.8.2; CIL 5.5262, 14-15. «(...) item bybliothecam et IN TVTELAM.BYBLIOTHECAE.HS.C». 
retur; nunc ista conquisita, cum imaginibus suis discripta, sacrorum opera ingeniosum in speciem et cultum parietum comparanturs ${ }^{10}$ y sigue arremetiendo: «Non fuit elegantia illud aut cura, sed studiosa luxuria, immo ne studiosa quidem, quoniam non in studium, sed in spectaculum comparaverant, sicut plerisque ignoris etiam puerilium litterarum libri non studiorum instrumenta, sed cenationum ornamenta». ${ }^{11 .}$

Según se desprende de lo que acabamos de ver, Cayo pudo haber formado bibliotecas particulares con aquellos libros que le pudieran interesar pero no públicas, bien por la brevedad de su principado o bien porque realmente no era necesario en ese momento construir ninguna nueva, bastando con las existentes, lo cual era un síntoma de la mesura con la que estaba llevando a cabo su tarea de gobierno. Esta actuación es confirmada por su sucesor Claudio, a pesar de su clara inclinación hacia el estudio y la erudición, lo cual debía disponerle de forma natural a la creación de una gran biblioteca. Conocemos por Suetonio algunas de las obras por él escritas ${ }^{12}$, empezando por las históricas que bajo el consejo de Tito Livio redactó sobre los sucesos acaecidos después del asesinato de César en duo volumina, luego la época que se inició posteriormente a la guerra civil en uno et qudraginta (volumina); además de estos escribió una autobiografía en octo volumina, una defensa de Cicerón titulada Ciceronis defensionem adversus Asinii Galli libros ${ }^{13}$ y una obra justificando la existencia de tres letras que había inventado. Por otra parte, también dominaba el griego y en esta lengua escribió veinte libros dedicados a los etruscos y ocho a los cartagineses.

De cualquier forma, si no nos queda constancia de construcciones para bibliotecas en la propia Roma, Claudio sí demostró interés por el complejo de Alejandría, al cual añadió un nuevo museo con su biblioteca, cosa que no intentó ni siquiera Calígula a pesar de todo su interés por esta ciudad.

Si nos remontamos hasta la época de Julio César, podemos ver que tanto él como Augusto y Tiberio tuvieron inquietudes intelectuales de diversa índole, lo cual pudo influir en la construcción de las primeras bibliotecas públicas, inexistentes hasta ese momento, entre otro de tipo de motivaciones como el evergetismo. Julio César, quien además de sus comentarios escribió otras obras, como testimonia Suetonio ${ }^{14}$ : "Feruntur et a puero et ab adulescentulo quodam scripta, ut Laudes Herculis, tragoedia "Oedipus», item "Dicta collectanea», se dispuso a abrir al público bibliotecas griegas y latinas ${ }^{15}$, pensando para este último proyecto en Marco Varrón para que se encargara de la compra de los libros así como de su clasifica-

10 Séneca. De tranquillitate animi. IX.7.

11 Ibid. IX.5.

12 Suetonio, Claudio. 41.1-3.

${ }^{13}$ Este Asinio Galo era hijo de Asinio Polión, senador e historiador. De su pluma salió una historia que narraba los acontecimientos sucedidos después de la batalla de Actium en diecisiete libros, según transmite Horacio en Carmina, 2,1, además de haber sido el fundador de la primera biblioteca pública de Roma, vid. Suetonio, Augusto, 29.

${ }^{14}$ Suetonio, César, 56.7.

15 Ibid. 44,2.; Fernandez Uriel, P.; Rodríguez Valcarcel, J.A.: «Julio César y la idea de biblioteca pública en la Roma antigua», Antigüedad y Cristianismo, XXIII (2006), pp. 965-979. 
ción, hacia los años 47-46 a.C. ${ }^{16}$ Su asesinato en marzo de 44 interrumpió el desarrollo de la biblioteca hasta que en el año 39 , uno de sus seguidores, el ya mencionado Asinio Polión, abriera una biblioteca, la primera de carácter público, situada en el foro y dividida en una sección griega y en una sección latina como había ya planeado César ${ }^{17}$.

Tras la finalización de las guerras civiles, una consecuencia más o menos inmediata debió ser la elevación del nivel de vida, lo cual siempre supone disponer de más recursos y más tiempo dedicados a la cultura; por ello, no es extrañar el auge experimentado por los programas tanto de reconstrucción como de nuevas construcciones que Augusto se aplicó a acometer. Por otra parte, este príncipe, cuya asombrosa talla política se dejó sentir fuertemente a lo largo de los gobiernos de sus sucesores, fue también autor de diversas obras que enumera Suetonio ${ }^{18}$ : unas en prosa como Rescripto Bruto de Catone, Hortationes ad philosophiam o De vita sua; otras en verso como Sicilia; paralelamente tuvo renombrados maestros a su disposición como Apolodoro, fundador de una escuela de retórica, Atenodoro de Tarso, Areius o Xenarco ${ }^{19}$, todo lo cual no dejaría de influirle en sus inquietudes intelectuales. Quizá fruto de ellas, de su programa evergético y posiblemente de la relación con autores coetáneos de gran fama, resultó la fundación de dos bibliotecas públicas. La primera en el Palatino en las cercanías de su propia casa, en el templo de Apolo, con motivo de la commemoración de la batalla de Actium ${ }^{20}$. La inauguración se produjo al parecer en octubre del año 28 a.C. y el resultado fue una biblioteca geminada, es decir, con una sección griega y otra latina en dos salas separadas ${ }^{21}$. Esta biblioteca parece que tuvo usos polivalentes como ser el lugar de reunión del senado o de recepción de embajadores entre otros.

16 Varrón había sido amigo de Pompeyo, ocupando en aquel tiempo diversos cargos en la administración romana como el tribunado de la plebe o la pretura; había formado parte también de una comisión que había estado encargada de realizar repartos de tierras. Finalmente, fue legado de Pompeyo en la guerra contra los piratas y luego en Hispania Ulterior. Retirado de la política, fue cuando recibió el encargo de César. Su reputación intelectual era tal que Plinio, Naturalis Historia, VII.xxx.115 escribió «M. Varronis in bibliotheca, quae prima in orbe Asinio Pollione ex manubiis publicata Romae est, unius viventis posita imago est (...)". escribió una obra titulada de bibliothecis, quizá dedicada al propio César, vid.: Boissier, G.: Etude sur la vie et les ouvrages de M. T. Varrón, París, 1986.

17 Zecchini, G.: «Asinio Pollione: Dall'attivitá politica alla riflessione storiografica», ANRW, 30.2 (1982), pp. 1265-1296; Andre, J.: La vie et Poeuvre d Asinius Pollion, Paris, 1949; Bosworth, A.B.: "Asinio Pollio and Augusto», Historia, 21 (1972), pp.441-473; DIX, T.K.: Private and public libraries at Rome in the first century B.C.: a preliminary study in the history of roman libraries, Michigan:UMI, 1994. "The location which best fits the available evidence is on the northwest slope of the Arx at the top of the clivus Argentarius, in an area later occupied by the Forum of Trajan and the rebuilding of the Forum lulium», p. 201.

18 Suetonio, Augusto, 89.3.

19 Parker, E.R.: «The education of heirs in the julio-claudian family», American Journal of Philology, 67 (1946), pp. 29-50, esp., pp. 32-33.

20 Suetonio, 29.3. «Templum Apollinis in ea parte Palatinae domus excitavit (...); addidit porticus cum bibliotheca Latina Graecaque (...)».

21 Castagnoli, F.: «Sulla biblioteca del tempio di Apollo Palatino», en Atti della Accademia Nazionale dei Lincei, IV.5-6 (1949), pp. 380-382 «La biblioteca del porticus ad apollinis è ancora conservata in parte, nella ricostruzione flavia, ed è anche delineata in un frammento della Forma Urbis Severiana (...). Che la ricostruzione flavia seguisse il precedente augusteo e molto probabili al meno per l'ubicazione e la proporzioni generali. Essa è costituita da due spaziose aule, che si aprivano direttamente sul portico (...)», p. 381. 
Años después inauguró una tercera biblioteca que se ha venido denominando pórticos de Octavia, en la zona sur del Campo de Marte. El nombre lo tomó el edificio en honor de la hermana de Augusto. Se trataba de un lugar ya antiguo de edificación con al menos ciento treinta años de antigüedad cuando en el año 33 a.C. se inauguró la restauración. Una década más tarde, Octavia se comprometió a reconstruir el complejo adyacente, añadiendo una curia o lugar de reunión, una schola, un pórtico y una biblioteca que fue dedicada a su hijo Marcelo $^{22}$, fallecido precisamente ese año. Tanto de ésta como de la de Polión no quedan restos, pero si de la Palatina, la cual nos sirve para delimitar la doble estructura de la misma y los nichos de las paredes destinados a recibir los «armaria» para disponer en ellos los volúmenes, según ya habíamos visto en la villa de Plinio o en los restos de la casa de Calígula. En cuanto al espacio interior, no se disponían como las griegas, en las que en un reducido habitáculo se depositaban las obras, las cuales luego se sacaban a un pórtico para ser leídas o consultadas. En las romanas posiblemente existirían mesas y sillas en el centro de las salas, donde los lectores podrían desarrollar su trabajo confortablemente y, en el caso de las bibliotecas asociadas a templos, también podrían utilizarse los pórticos columnados ${ }^{23}$. Desgraciadamente tanto la Palatina como el pórtico de Octavia sufrieron destrucciones en el incendio del 64 d.C. y luego en 191 d.C. en el primer caso y en el 80 d.C. en el segundo, siendo restauradas por el emperador Domiciano ${ }^{24}$, pero los originales de los escritores y las obras antiguas seguramente fueron pasto de las llamas.

Del sucesor de Augusto tenemos menos noticias sobre sus inquietudes intelectuales. Si sabemos que Tiberio era aficionado a ciertos poetas cuyos retratos puso en las bibliotecas, que escribió unas memorias no conservadas y que había sido seguidor de Marco Valerio Mesala Corvino y de Teodoro de Gádara. Por lo que respecta a las bibliotecas, fundó una en el Palatino, en el templo de Augusto y, quizá, una segunda en la domus tiberiana en opinión de Casson ${ }^{25}$, siendo la primera mencionada por Plinio y la segunda por Aulo Gelio ${ }^{26}$. Suetonio menciona, como ya hemos visto, la colocación de diversos retratos de los poetas Euforión, Riano y Partenio en las bibliotecas públicas ${ }^{27}$.

22 Richardson, L.: «The evolution of the Porticus Octaviae», American Journal of Archaelogy, 80.1 (1976), pp. 57-64. Empleados de la biblioteca fueron enterrados en la tumba de la hija de Octavia, Marcela. Plinio, Naturalis Historia, xxxix.31, llama a este complejo Octavia opera.

23 Vitrubio recomienda ubicarlas hacia Oriente, 6,4,1: «(...) cubicula et bibliothecae ad orientem spectare debent; usus enim matutinum postulat lumen, item in bibliothecis libri nos putrescent. Nam quaequmque ad meridiem et occidentem spectant, ab tiniis et umore libri vitiantur, quod venti umidi advenientes procreant eas et alumnt infundentesque umidos spiritus pallare volumina corrumpunt».

24 Suetonio, Domiciano, 20,1: «(..) quanquam bibliothecas incendio obsumptos impensissime reparare curasset, exemplaribus undique petitis missisque Alexandream qui describerent emendarentque».

25 Casson, L.: Libraries in the Ancient World, p. 84 Lipsio menciona que Galeno en el Libro I de la obra De compositione medicamentorum recoge que Tiberio disponía de una biblioteca en su palacio en la parte que daba a la Vía Sacra.

${ }^{26}$ Plinio, Naturalis Historia, xxxiv.xviii.43: «Videmus certe Tuscanicum Apollinem in bibliotheca templi Augusti quincuaginta pedum a pollice», Aulio Gelio, Noches Aticas, 13,20.1 «(...) a domus Tiberianae bibliotheca».

27 Suetonio, Tiberio, 44.2. Euforión pertenece al siglo III a.C., Riano de Creta fue contemporáneo del anterior y Partenio de Nicea era de la época de Augusto. Había sido maestro de Virgilio y cultivador de la poesía erótica. 
Si Tiberio, como en toda su actuación, fue austero en cuanto a la construcción de nuevas bibliotecas, este momento tiene mucha importancia puesto que con $\mathrm{Ti}$ berio precisamente parece crearse el cargo de procurator bibliothecarum, según figura en una inscripción funeraria de Tiberio Claudio Scirto ${ }^{28}$, quien había sido liberto de Augusto y un servidor de la casa imperial, pero no un intelectual y un literato como los demás personajes que habían estado al frente de las bibliotecas con anterioridad. Hemos visto que César encargó a Varrón no sólo la compra de libros sino su organización. Asinio Polión, escritor él mismo, seguramente se encargó personalmente en lo que se refiere a ls compras y redacción del catálogo, organización de su biblioteca en el Atrium Libertatis. Con Augusto, las bibliotecas fueron encomendadas, por un lado, a Gneo Pompeyo Macer $^{29}$ en la Palatina, poeta y autor de obras épicas, y a Cayo Meliso en el Pórtico de Octavia, quien había sido manumitido por Mecenas, según recoge Suetonio en De grammaticus et Rhetori$b u s^{30}$, donde también proporciona información sobre el sucesor de Macer, el también liberto C. Julio Higinio: «C. Iulius Hyginius, Augusti libertus, natione Hispanus (...) ${ }^{31}$, gran amigo de Ovidio y del historiador Clodio Licinio ${ }^{32}$, fue autor de numerosas obras de tema diverso: agricultura, historia o teología. Con Tiberio, Calígula y Claudio trabajaron el ya mencionado Scirto y Tiberio Julio Papo, íntimo amigo de Tiberio $^{33}$. Poco a poco los cargos de dirección de bibliotecas se fueron burocratizando, caso de Scirto, como consecuencia de la mayor complejidad de los servicios de la nueva administración imperial y que se hallaba todavía en manos de los libertos y algo más tarde en la de los miembros del orden ecuestre ${ }^{34}$.

Además de los nombres asociados a estos cargos, conocemos otros cuantos relativos al personal que atendía los distintos servicios prestados en las bibliotecas: como los encargados del mantenimiento de edificio, denominados vilicus ${ }^{35}$ :

DECVRIO

HYMNVS

AVRELIANVS

${ }_{28}$ CIL 10.1739; Rodríguez Valcarcel, José A.: «Procurator Bibliothecae Augusti: Los bibliotecarios del emperador en los inicios de las bibliotecas públicas en Roma», Anales de Documentación, 7 (2004), pp. 231-239.

29 Suetonio, César, 56.7 «...) Pompeium Macrum, cui ordinandas bibliothecis delegaverat (...)».

30 Suetonio, XXI.1 «C. Melissus, Spoleti natus ingenuus (...)» y XXI.3 «Quo delegante curam ordinandarum bibliothecarum».

31 Ibid. XX.1.

32 Ibid. XX.2 «Praefuit Palatinae bibliothecae (...) fuitque familiarissimus Ovidio poetae et Clodio Licino consulari historico (...)».

33 Van Buren, A.W.: «News letter from Rome», American Journal of Archaelogy, LXIII (1959), pp. 383-394. Su lápida sepulcral es reproducida por este autor y dice: «D(is) $M$ (anibus)/Ti(berio) Iulio, Zoili f(ilio), F(abia tribu), Pappo,/ comit(i) Ti(beris) Caesaris Aug(usti), idemq(ue)/supr(a) bybliothecas omnes Augustorum/ab Ti(berio) Caesare usque ad Ti(berium)/Claudium Caesarem./Per Ti(berium) Iulium Niconem hered(em)/in parte quarta e lulia(m) Fortun(atam).», p.384.

34 Tenemos el caso de L. Vestinus quien fue designado por Vespasiano para dirigir los trabajos de reconstrucción del Capitolio, vid. Tácito, Historias, IV.53.

35 CIL. 6.4431; Brunt, P.A.: «Free labour and public works at Rome», Journal of Roman Studies, 70 (1980), pp. 81-98 «(...) we may suppose that similar functions were discharged by the various curators and other offcials concerned with public and sacred buildings (...)», p. 85. 


\title{
A. BYBLIOTHECE
}

\section{LATINA P PORTICVS \\ OCTAVIAE \\ VILICVS}

Otros se dedicarían a colocar los rollos, a copiarlos y restaurar los más deteriorados en cada una de las secciones, latina o griega, en las cuales trabajaban en función de su especialización ${ }^{36}$, denominados a bibliothecis:

\author{
ALEXANDER $\cdot \mathrm{C} \cdot \mathrm{CAE}$ \\ SARIS · AVG - GERMANICI - SER \\ PYLAEMENIANVS $\cdot A B \cdot B Y B L I$ \\ OTHECE · GRAECA · TEMPLI $\cdot$ APOLLI \\ NIS $\cdot$ VIX $\cdot$ ANNIS $\cdot$ XXX
}

Poco o nada sabemos sobre la organización de los fondos en estas bibliotecas, aunque es posible que utilizaran el sistema que inventó Calímaco para la de Alejandría, es decir, dividiendo los autores entre las categorías de prosa y poesía; dentro de ésta incluiría a los poetas dramáticos, los de comedia, los líricos y los épicos. Luego estarían, por otra parte, los prosistas, divididos en filósofos, oradores e historiadores. Sus Pínakes o tablas de autores se organizaban por orden alfabético, contando con una pequeña biografía y la lista de las obras igualmente alfabética. Los volúmenes se colocaban en los armaria, en posición horizontal y con un titulus que permitía conocer al autor y la obra, la cual estaría localizada en un número de armarium determinado ${ }^{37}$.

En cuanto a los fondos propiamente dichos, las colecciones, divididas en autores griegos y latinos, dispondrían de copias de Homero, Eurípides o Menandro así como de Ennio, Plauto o Virgilio, además de obras de filósofos, historiadores como Livio ${ }^{38}$ y de otros que trataron temas de carácter técnico como Columela, tanto antiguos como modernos ${ }^{39}$. Por lo que respecta a la adquisición de estos fondos, posiblemente algunos se obtuvieran de los bibliopolae de la ciudad de Roma, por donaciones de los propios autores o procedentes de bibliotecas privadas o de confiscaciones como pudo suceder con la de Varrón, confiscada por M. Antonio, la de Lúculo, Sila o Atico.

En relación con los autores y las bibliotecas, es de destacar la función «política» de éstas, ya que los escritores que eran anatematizados con condenas políticas o literarias sufrían una especie de damnatio memoriae, lo cual implicaba también un control cultural por parte del régimen, como demuestra la orden dada por

${ }^{36}$ CIL, 6.5188.

37 F. Vopisco en la Historia Augusta, vida de Tácito, 8.1 escribía que «(...) habet in bibliotheca Ulpia in armario sexto librum elephantinum in quo hoc in quo senatus consultum (...)».

38 Marcial, 12.190 «(..) pellibus exiguis ortatur Livius ingens/quem mea non totum bibliotheca capit.»

39 Ovidio, Tristia, III.1.63-64. «Quaque viri docto veteres cepere novique/pectore lecturis inscipienda patent». 
Augusto a Pompeyo Macer para que no estuvieran accesibles al público unos trabajos de juventud de Julio César ${ }^{40}$. En este mismo caso nos encontraríamos con el proyecto de Calígula de hacer retirar de las bibliotecas las obras de Virgilio y Tito Livio $^{41}$ o con el ejemplo de Ovidio, quien en los Tristia se dirige a Julio Higinio para que sus obras fueran rehabilitadas ya que «Est fuga dicta mihi, non est fuga dicta libellis» ${ }^{42}$, encomendándole el que se encuentra escribiendo ${ }^{43}$.

Un problema es el grado de accesibilidad que estas bibliotecas «públicas» tenían, si realizaban préstamos o no, es decir, si estaban abiertas a todo el mundo o bien únicamente a unos cuantos amigos y clientes del emperador así como para su uso por él mismo como depósito de la memoria cultural colectiva del estado, ya que si este fuera el caso la repercusión de la damnatio sería mínima. Bien es cierto que la quema de libros de un autor determinado se producía por orden del senado, lo cual le confería una oficialidad extensible, posiblemente, a todos los ámbitos, públicos y privados.

\section{LIBROS}

Sin entrar en la descripción de las características físicas del libro entre los romanos, vamos a centrarnos en su difusión y circulación, ya que es el aspecto que se relaciona directamente con el asunto de la reaparición en época de Calígula de las obras de varios autores prohibidos años atrás, así como con las críticas literarias que efectuaba hacia las obras de otros autores, lo cual para escritores como Suetonio era un síntoma de locura, punto de vista, en mi opinión, un tanto partidista y tendencioso.

En la Roma republicana la publicación inicial de los libros se realizaba a través de las copias de los manuscritos originales ${ }^{44}$ y de aquí pasaban de mano en mano. Posteriormente, ya en los comienzos del imperio se realizaban de manera oral, organizando lecturas públicas y en muchas ocasiones privadas delante de amigos o compañeros literatos. Parece ser que el primero en organizar estas lecturas fue Polión ${ }^{45}$, aunque no sería del todo exacto puesto que las recitaciones eran ya conocidas entre los romanos y lo que innovó fue posiblemente la distribución de invitaciones entre todos aquellos que tuvieran interés en asistir a las lecturas en el Atrium Libertatis, lo cual era también bastante habitual en el mundo helenístico. Algo más tarde Virgilio y Horacio eran aclamados por las suyas e,

40 Suetonio, César, 56; vid. Marshall, A.J.: «Library resources and creative writing at Rome», Phoenix, xxx.3 (1976), pp. 252-264.

${ }^{41}$ Suetonio, Caligula, 34.2 «(..) ex omnibus bibliothecis amoveret».

42 Ovidio, Tristia, III.9.

43 Ovidio, Tristia, III.14.49 «Crede mihi, timeo ne sint inmisxta latinis/Inque meis scriptis Pontica verba legos/Qualemcumque igitur venia dignare libellum, /Sortis et excusa condicione meae».

${ }_{44}$ Dilke, O.A.W.: Roman books and their impact, Leeds, 1977, pp. 19-20.

45 Séneca el viejo, Controversiae IV. Praefatio 2. «(...) primus omnium Romanorum advocatis hominibus scripta sua recitavit», vid. Dalzell, A.: «C. Asinius Pollio and the Early History of public recitation at Rome», Hermathena, Ixxxvi (1955), pp. 20-29. 
incluso, el emperador Claudio ofreció recitaciones de sus obras ${ }^{46}$, lo que prueba la rápida difusión del método. Muchas de ellas fueron organizadas por los propios editores de los escritores que les facilitaban sus obras. La figura de éstos era muy importante puesto que constituían los intermediarios entre el autor y los potenciales receptores de las obras, ya fueran personas privadas o bien las bibliotecas públicas. El primero que desarrolló una actividad editora de cierta importancia fue Pomponio Atico, cuyas copias eran demandadas en todo el orbe romano e, incluso, parece que algún artificio mecánico para la reproducción pudo haber utilizado en su taller, ya que un libro de Varrón que fue publicado por él constaba de setecientos retratos, probablemente fundamentales al tratarse de una obra con biografías, constituyendo una tarea ardua, lenta y costosa reproducir manualmente cada uno de estos retratos.

Los editores eran al mismo tiempo libreros o, por mejor decir, bibliopolae, llamados también librarii, los cuales tenían a su servicio a esclavos especializados para la copia de las obras, los denominados servi litterati o servi librarii ${ }^{47}$, aunque no podemos saber exactamente de cuántos ejemplares constaba cada una de las tiradas. Los autores no recibían por ellas ninguna retribución ni tampoco existían derechos de autor que les aseguraran unos ingresos sobre las ventas; es más, cualquiera podía sacar todas las copias que quisiera, tanto de libros comprados en las librerías como de las que pudieran existir en las bibliotecas, de las que no se tiene información amplia sobre si servían libros en préstamo o no ${ }^{48}$. En la zona de Argiletum parece que existían muchas librerías, a la puerta de las cuales se exponían listas en las que figuraban los nombres de los poetas que se vendían, como escribe Marcial ${ }^{49}$ :

\section{«Argi nempe soles subire Letum contra Caesaris est forum taberna scriptis postibus hinc et inde totis, omnis ut cito perlegos poetas: illinc me pete. Nec roges Atrectum- hoc nomen dominus gerit tabernae-; de primo dabit alteroue nido rasum pumice purpuraque cultum denaris libri quinque Martialem»}

Vemos aquí como se confeccionaban libros con exquisito gusto que eran precisamente los más caros y para los que elaboraban los receptáculos más lujosos y

46 Suetonio, Claudio, 41.

47 Estos cobraban por línea y la rapidez del trabajo también suponía la existencia de errores, cuestión muy importante para todos los autores, vid. Kleberg, T.: «Comercio librario y actividad editorial en el Mundo Antiguo», en Cavallo, G.: Libros, editores y público en el Mundo Antiguo, Madrid, 1995 , pp.64-106.

48 A excepción de la anécdota que señala Aulo Gelio en las Noches Aticas. XIX.5.

49 Marcial, Epigrammaton, I.17 o bien I.3 «Argiletanos mauis habitare tabernas/cum tibi parve liber, scrinia nostra vacent». 
de los que Séneca se queja: «Quid habes cur ignoscos homini armaria e citro atque ebore captanti (...) $)^{50}$. El incremento de estos comercios era natural tras la pacificación que supuso el final de las guerras civiles y el previsible aumento general del nivel de vida que hizo que Roma se convirtiera en un polo de atracción para maestros, estudiantes y autores de todas las clases y condiciones así como para la formación de bibliotecas privadas y la gran compra de libros por particulares, como sigue escribiendo Séneca: «(...) corpora conquirenti aut ignotorum auctorum aut improbatorum et inter tot milia librorum oscitanti, cui voluminum suorum frontes maxime placent titulique?»51, o bien, "Studiorum quoque qua liberalissima impensa est, tandius rationem habet quamdiu modum. Quo innumerabilis libros et bibliothecas, quorum dominus, vix tota vita indices perlegit?»52.

Conocemos los nombres de otros editores y libreros de Roma, algunos de los cuales estaban especializados en literatura corriente, otros en libros antiguos o en determinados autores. Horacio escribe en una de sus epístolas: «Votumnum lanumque, liber spectore videris/scilicet ut prostes Sosiorum pumice mundus" ${ }^{53}$ o en De arte poetica: «(...) hic meret aera liber Sosiis hic et more transit/et longum noto scriptori prorogat aevum ${ }^{54}$, Séneca nombra a un tal Doro: «Libros decimus esse Ciceronis; eosdem Dorus librarius suos vocat, et utrumque verum est; alter illos tamquam auctor sibi, alter tamquam emptor adserit; ac recte utriusque dicuntur esse, utriusque enim sunt, sed non eoden modo. Sic potest Titus Livius a Doro accipere aut emere libros suos» ${ }^{55}$.

Con tal cantidad de libreros, copistas, compradores y copias en circulación no hubiera sido difícil recuperar obras que hubieran desaparecido o hubieran sido prohibidas como es el caso de las de Aulo Cremucio Cordo, Tito Labieno y Casio Severo, autorizadas de nuevo con Calígula ${ }^{56}$. Con la instauración de régimen imperial por parte de Augusto, se dio lugar a la división entre algunos escritores partidarios del régimen y que incluso forjaron una imagen a medida para Octavio como fue el caso de Horacio, Virgilio u Ovidio, y aquéllos que se refugiaron en posiciones republicanas opuestas a la desaparición de la «libertas» ${ }^{57}$ y en torno a círculos más

50 Séneca, De tranquillitate animi, IX.6.

51 Ibid. IX.6.

52 Ibid. IX.4.

53 Horacio, Epistuli, XX.1. Los hermanos Sosio publicaron las obras de Horacio.

54 Horacio, De arte poética.345.

55 Séneca, De beneficiis, VII.vi.1.

56 Suetonio, Calígula, 16.1 «Titi Labieni, Cordi Cremuti, Casi Severi scripta senatus consultis abolita requiri et esse in manibus lectitorique permissit (...)».

57 André, J.M.: «La conception de l'Etat et l'Empire dans la pensée gréco-romaine des premiers siècles de notre ère», en ANRW (1973), 30.1, pp. 3-73, «(...) la libertas a pour forme positive le ius consendi au Senat, qui disparaître nettement sour Tibére. Sous Auguste, le republicanisme s'abrite derriere les allusions frequantes a le tyrannie. Les oppossants Cassius Severus, Labienus, Albutius Silius (...) n'avaient pas de doctrine constitutionelle, hormis le culte de la liberté dexpression avec laquelle ils voulaient mettre de principat en contradiction; ils choissisent comme terrain delection les iudicia, dont l independence etait pour Ciceron un critere de liberté».; vid. Rodríguez Valcarcel, José A.: «Oderint dum metuant: el desarrollo del Gobierno de Cayo César en la ficción del principado». Madrid: Fundación Universitaria Española, 2004. 
o menos relacionados con el estoicismo ${ }^{58}$, aunque en un principio Calígula no parece demostrar ninguna animadversión por sus críticas, como muestra el hecho de que ordenara la circulación de Tito Labieno, quien pertenecía a una familia de rancia raigambre republicana.

Tito Labieno era un temible orador cuando atacaba los vicios de su época y de ahí que fuera llamado Rabieno ${ }^{59}$. Casio Severo, también incluído dentro de estos grupos republicanos, había visto quemar las obras de su colega hacia el 12 d.C. ${ }^{60}$ y las suyas que iban en contra de ilustres personajes contemporáneos, por lo cual fue exiliado a Creta y luego a Sérifo por Tiberio, donde murió finalmente ${ }^{61}$. La quema de los libros parece que estaba a cargo de los ediles ${ }^{62}$ en razón de la cura urbis, pudiendo dejar la ejecución material a los tresviri capitales, como Tácito menciona en su obra Agricola recordando la quema de los libros de Rustico y Seneción ${ }^{63}$. En el caso de Cremucio Cordo, senador y personaje de gran prestigio, ${ }^{64}$ la delación vino de la mano de Satrio Segundo y Pinario Nata, que actuaban por orden de Sejano, bajo la acusación de que había escrito unos anales y en ellos había alabado a Marco Bruto y había llamado el «último de los romanos» a Casio ${ }^{65}$. Finalmente fue decretado por el senado que los libros fueran quemados por los ediles: «Libros per aediles cremandos censuere patres», y esta condena parece que se extendía no solamente por Roma sino también por el resto del imperio.

En el caso de Cordo, Calígula ordenó que fueran buscadas las obras, requiri, lo cual significa que no se encontraban disponibles en las bibliotecas públicas, como es lógico, sino que estuvieran únicamente en manos privadas de manera secreta, como Tácito ${ }^{6}$ menciona: «(...) set manserunt occultati et editi». Según parece esto fue hecho por su hija Marcia, como describe Séneca ${ }^{67}$ : «Ut vero aliquam occasionem mutatio temporum dedit, ingenium patris tui, de quo sumptum erat supplicium, in usum hominum reduxisti et a vera illum vindicasti morte, ac restituisti in publica monumenta libros quos vir ille fortissimus snguine suo scripserat». Quizá pudieran haber circulado expurgadas de

58 Brunt, P.A.: «Stoicism and the principate», Papers of the British School at Rome, XXXI (1975), pp. 6-35 «It was under Gaius, Nero, Vespasian and Domitian that stoics certainly suffered persecution (...)», p. 9 .

59 Séneca el viejo, Controversiae X.4.17.

60 Ibid. Praefatio. 8 "Quanta in illis libertas fuit quam etiam Labienus extimuit; Cassi Severi, hominis Labieno invisissimi, belle urebantur: nunc me, inquit vivum uri oportet, qui illos edidici. Monstrabo beIlum vobis libellum quem a Gallione vestro petatis. Recitavit rescriptum Labieno pro Bethyllo Maecenatis, in quo suspicietis adulescentiis animum illos dentes mordentum provocatis».

61 Tácito, Annales. IV.21; Rostagni, A.: Storia della letteratura latina, II. Parte Prima: da Augusto a Nerone. Torino: Unione tipografica-Editrice Torinese, 1964, pp. 414-418.

62 Kleberg, T.: Comercio librario.... p. 97; Cramer, F.: «Book burning and censorship in Ancient Rome», Journal of the History of Ideas, 1945.

63 Tácito, Agricola.2.1.

64 C., M.: «ll processo di Cremuzio Cordo», en Atene e Roma, IV.35 (1901), pp. 362-382.

65 Tácito, Annales, IV.xxxiv. «Cornelio Cosso Asinio Agripa consulibus Cremutius Cordus postulator, novo ac tunc primum auditio crimine, quod editis annalibus laudatoque $M$. Bruto C. Cassium Romanorum ultimum dixisset». Canfora, L.; Roncalli, R.: Autori e testi della letteratura latina, Roma-Bari: Laterza, 1993, pp. 718-719.

66 Tácito, Annales, IV.xxxv.

67 Séneca, Ad Marciam de Consolatione, 13.3. 
aquellos pasajes comprometedores o bien que lo hubieran sido después y ahí el permiso para que reaparecieran, pero es bastante difícil que procedentes de bibliotecas privadas, sus posesores pudieran declarar que habían guardado libros prohibidos por el emperador y el senado. Otras posibilidades para recuperar estos libros quizá deberíamos buscarlas en la gran biblioteca de Alejandría.

Esta biblioteca fue, desde sus orígenes, una biblioteca griega, de modo que es probable que la práctica totalidad de los fondos estuvieran en griego y procedieran de autores griegos también ${ }^{68}$, aunque figurarían obras de historiadores no griegos, traducidos a esta lengua e incluso obras originales en latín ${ }^{69}$, dado el bilingüismo imperante entre las clases cultas usuarias potenciales de estas primeras bibliotecas públicas. Aquí encontramos la razón de que Domiciano enviara copistas ${ }^{70}$ para restaurar las obras perdidas en los incendios de las bibliotecas de Roma y no existe motivo alguno para pensar que las obras que Calígula había autorizado a buscar y poner en circulación, no estuvieran en Alejandría, desplazando así a personal bibliotecario para realizar las copias.

Si Cayo tenía interés en que «(...) ut facta quoque posteris traduntur», es decir, por la memoria histórica, no era menor el que demostraba por obras de los más variados géneros literarios como la filosofía o la poesía y no sólo por las piezas oratorias, en contra de lo que Suetonio afirma: «Ex disciplinis liberalibus minimum eruditioni, eloquentiae plurimum attendit(...) $)^{71}$. Ello se demuestra no sólo por la recuperación de las obras históricas anteriores sino también por sus opiniones críticas efectuadas hacia autores de gran prestigio: Virgilio, Titio Livio, Homero y Séneca, muchos de las cuales fueron también compartidas por otros autores contemporáneos de los mismos escritores o posteriores. Escribe Suetonio: «Sed et Vergilii ac Titi Livi scripta et imágenes paulum afuit quien ex omnibus bibliothecis amoveret, quorum alterum ut nullius ingenii minimaeque doctrinae, alterum ut verbosum in historia neglegentemque carpebats ${ }^{72}$. Con respecto a Virgilio, Cayo le reprochaba su falta de ingenio y erudición y el propio Suetonio en su De viris illustribus, en la vida de Virgilio enumera a los detractores de Virgilio ${ }^{73}$ como Numitorio que escribió unas Antibucólicas, Corvilio Pictor un libro contra la Eneida, titulado Aeneomastix, Herennio que recogió en otra obra todos sus defectos, Parelio Fausto sus plagios o Avito, quien en ocho volúmenes de omoiotetes, que contenían todos los versos que Virgilio había copiado de otros autores, proporcionando su procedencia. Como hemos visto la lista es extensa ${ }^{74}$. Por lo que se refiere a Tito Livio,

68 Escolar Sobrino, H.: La biblioteca de Alejandría, Madrid: Gredos, 2001.

69 EL Abbadi, M.: La antigua biblioteca de Alejandría, UNESCO, 1994. Este autor menciona la carta de Aristeo del siglo II a.C. en la que se afirma que Demetrio de Falero había recibido muchos fondos para comprar ejemplares de todos los libros existentes en el mundo y el texto medieval de Tzetzes, extraído de una fuente antigua, corrobora que la compra de libros no se limitaba a autores griegos sino que abarcaba todas las nacionalidades.

70 Suetonio, Domiciano, 20, 1. «(..) quamquam bibliothecas incendio obsumptos impensissime reparare curasset, exemplaribus undique petitis missisque Alexandream qui describerent emendarentque».

71 Suetonio, Caligula, 53.

72 Ibid. 34,2.

73 Suetonio, Vida de Virgilio, 43. 
ya Asinio Polión le había criticado duramente, como transcribe Quintiliano en las instituciones oratorias: «(...) quem ad modum Pollio reprendit in Livio patavinitatem $»^{75}$ y también «(...) et in Tito Livio, mirae facundiae viro, putat inesse Pollio Asinius quondam «patavinitatem» ${ }^{76}$.

De Homero decía que quería destruir sus poemas: «Cogitavit etiam de Homeri carminibus abolendis, cur enim sibi non licere, dicens, quod Platoni licuisset, qui eum e civitate quam constituebat eiecerit?»>77. La alusión de Calígula se está refiriendo a las críticas que Platón realiza en general en contra de los poetas, como representantes de un arte imitativo que crean en las gentes imágenes falsas y poco convenientes. La crítica se centra, sobre todo, en aquel que era considerado en el mundo griego como el máximo exponente de la poesía hasta entonces y así en el libro décimo de la República, se excluye a Homero de la ciudad que Platón propugna para ser regida por los filósofos, puesto que son los únicos que conocen la verdad de las cosas (X.595) y tampoco gracias a las obras de Homero se ha mejorado ninguna ciudad, de modo que no tiene cabida en aquéllas que quieran regirse por buenas leyes $(\mathrm{X} .607)^{78}$. Ante todo esto, vemos que si Platón excluía a Homero de su ciudad con motivos justificados, no parece lo mismo en el caso de Calígula, quien recurre al argumento de la autoridad para justificar su acción. Debemos tener en cuenta que únicamente quería eliminar los poemas de las bibliotecas pero no quemarlos. No obstante, este caso sirve como testimonio de las lecturas griegas de Calígula no sólo de la república platónica sino también de los poemas homéricos, los cuales eran utilizados frecuentemente ${ }^{79}$ en escritos como las vidas suetonianas, en las que pone en boca de sus personajes diversas frases entresacadas de los poemas, recordemos así el reto de Calígula a Júpiter o la calificación de su abuela Livia como un Ulises con faldas ${ }^{80}$, junto a la mención del poder único, aunque es posible encontrar citas de otras autores u obras griegas como Eurípides o Menandro, pero con preeminencia de Homero. Existiría, por tanto, una extraña contradicción: que Calígula quisiera eliminar de las bibliotecas, entendemos que públicas, las obras de Homero y, por otro lado, las estuviera utilizando constantemente. Podemos decir que, en este sentido, y con Cavallo ${ }^{81}$ que a través de las bibliotecas se pretendía en cierto modo controlar, o intentarlo cuando

74 También existieron partidarios como Pediano que escribió un libro contra los detractores de Virgilio. Incluso el mismo Virgilio quiso quemar la Eneida, vid. Vidal, J.L.: «Por qué Virgilio quería quemar la Eneida...si es que quería», Humanitas. In honorem A. Fontán, Madrid: Gredos, 1992, pp. 479-484.

75 Quintiliano, I.v.56.

76 Ibid. VIII.i.3. Este Polión estaba muy ligado a César y a Antonio, de modo que no le sería ajeno a Calígula, vid. Zecchini, G.: «Asinio Pollione: dall'attività politica alla riflesione storiografica, en ANRW 2 , 30, 2 (1982), pp. 1265-1296.

77 Suetonio, Caligula, 34.2.

78 Platón, La República, (Ed. Pabón, J.M.; Fernández Galiano, J.L.), Madrid, 1997.

79 Berthet, J.-F.: «La culture homérique des Césars d'après Suétone», Revue des Etudes Latines, 56 (1978), pp. 314-334.

80 Dión Casio, Historia romana, LIX.28.6, correspondiente a la Iliada XXII.724 y XXIII.3, aunque algunos fueran reales otros constituirían un recurso literario, de modo que se acomodaran los ejemplos homéricos a los comportamientos y reacciones de cada uno de los emperadores.

81 Cavallo, G.: «Entre el volumen y el codex. La lectura en el mundo romano», Historia de la lectura en el mundo occidental, Madrid, 1998, pp.97-133. Según este autor, la biblioteca palatina estaba encaminada a conservar un cierto patrimonio literario o las memorias escritas, civiles y religiosas, de Roma. 
menos, lo que se debía o no leer. Calígula en el texto de Suetonio parece estar defendiéndose de las críticas que se le pudieron efectuar ante su proyecto y su postura podría responder, por tanto, a un deseo de intervención en la cultura de las gentes de Roma, en función de esa crítica literaria como la que si realiza a los escritos de Séneca, los cuales no quiere prohibir ni retirar de las bibiotecas, las cuales hay que suponer que en ellas estaban.

En efecto, Séneca se llevó, si cabe, algunas de las peores críticas de Calígula, como escribe Suetonio: «(...) comptiusque scribendi genus adeo contemnens, ut Senecam tum maxime placentem «commissiones meras» componere et «harenam sine calce", diceret ${ }^{82}$. Posiblemente no podría ser de otro modo, si tomamos en consideración las obras que, antes del asesinato del princeps en 41 d.C., había escrito o publicado aquél ${ }^{83}$. Tenemos noticias de que había escrito hacia el año 25 dos obras que no se conservan tituladas De situ et sacris Aegypti y De situ Indiae; hacia el año 31 y siguientes De lapidum natura, De piscium natura y De motu terrarum que tampoco han llegado hasta nuestros días. Hacia los años 39-40, se data Ad Marciam consolatione y del $41 \mathrm{De}$ ira, pero las demás obras son posteriores a la muerte de Cayo como las cartas a Lucilio, las tragedias, los diálogos, etc., de modo que las conocidas por Cayo al ser las primeras obras no tendrían la misma calidad que las posteriores. Desde esta perspectiva sí podemos admitir la mera crítica literaria, puesto que aunque hubiera existido un trasfondo de oposición hacia el estoicismo del cual Séneca era una buena muestra, con su crítica hacia la tiranía pero no del sistema implantado por Augusto, el cual se reconocía legitimado en la familia de los Césares $^{84}$, abogando por una monarquía justa ${ }^{85}$ y de naturaleza clemente como mejor organización para el estado. Estas últimas virtudes debían asimilarse al dominio de uno mismo cuando se tiene la potestad de castigar y de imponer castigos. En definitiva, si en Séneca puede existir una oposición a un gobierno como el que Calígula parecía estar desarrollando a través de sus escritos, en la actitud del príncipe no parece haber nada más que la expresión de una opinión sobre sus escritos. Recordemos en este punto el permiso que dio Cayo para que circularan obras de otros estoicos, conducta que no puede tacharse de arbitraria o irracional.

Hemos visto, pues, como en dos aspectos tan relacionados con el mundo cultural como son las bibliotecas y el libro, las actitudes de Calígula no fueron en modo alguno el resultado de las manías de un loco o de un incremento paulatino de la tiranía del régimen, no estando tampoco fuera de lo que había sido el comportamiento habitual de sus antecesores, todo lo cual puede constituir un punto de apoyo para tratar de que el resto de los acontecimientos que le tocaron vivir puedan ser situados en el justo lugar que les corresponde.

82 Suetonio, Caligula, 53.1.

83 Grimal, P.: Sénèque où la conscience de Pempire, Paris, 1978; Albertini, E.: La composition dans les ouvrages philosophiques de Sénèque, Paris, 1923.

84 Séneca, De clementia I.4.2.

85 Ibid. II.20.2 «(..) cum optimus civitatis status sub rege iusto sit (...)»; Fontan, A.: «La monarquía en Séneca», Gerión, 2 (1989), pp. 219-245. 


\section{BIBLIOGRAFIA}

ALBERTINI, E.: La composition dans les ouvrages philosophiques de Sénèque, Paris, 1923. ANDRE, J.: La vie et Poeuvre d'Asinius Pollion, Paris, 1949 BOSWORTH, A.B.: «Asinio Pollio and Augusto», Historia, 21 (1972), pp.441-473.

ANDRE, J.M.: «La conception de l'Etat et l'Empire dans la pensée gréco-romaine des premiers siècles de notre ère», $A N R W(1973), 30.1$, pp. 3-73.

BERTHET, J.-F.: «La culture homérique des Césars d'après Suétone», Revue des Etudes Latines, 56 (1978), pp. 314-334.

BOISSIER, G.: Etude sur la vie et les ouvrages de M. T. Varrón, París, 1986.

BRUNT, P.A.: «Free labour and public works at Rome», Journal of Roman Studies, 70 (1980), pp.81-98.

BRUNT, P.A.: «Stoicism and the principate», Papers of the British School at Rome, XXXI (1975), pp. 6-35.

CANFORA, L.; RONCALLI, R.: Autori e testi della letteratura latina, Roma-Bari: Laterza, 1993.

CASSON, L.: Libraries in the Ancient World, New Haven-London, 2001.

CASTAGNOLI, F.: «Sulla biblioteca del tempio di Apollo Palatino», en Atti della Accademia Nazionale dei Lincei, IV.5-6 (1949), pp. 380-382.

CAVALLO,G.: «Entre el volumen y el codex. La lectura en el mundo romano», Historia de la lectura en el mundo occidental, Madrid, 1998.

CRAMER, F.: «Book burning and censorship in Ancient Rome», Journal of the History of Ideas, 1945.

DALZELL, A.: «C. Asinius Pollio and the Early History of public recitation at Rome», Hermathena, Ixxxvi (1955), pp. 20-29.

DILKE, O.A.W.: Roman books and their impact, Leeds, 1977.

DIX, T.K.: Private and public libraries at Rome in the first century B.C.: a preliminary study in the history of roman libraries, Michigan:UMI, 1994.

EL ABBADI, M.: La antigua biblioteca de Alejandría, UNESCO, 1994.

ESCOLAR SOBRINO, H.: La biblioteca de Alejandría, Madrid: Gredos, 2001.

FONTAN, A.: «La monarquía en Séneca», Gerión, 2 (1989), pp. 219-245.

GRIMAL, P.: Sénèque où la conscience de lempire, Paris, 1978.

KLEBERG, T.: «Comercio librario y actividad editorial en el Mundo Antiguo», en G. CAVALLO: Libros, editores y público en el Mundo Antiguo, Madrid, 1995, pp.64-106.

MACMULLEN, R.: «Two notes on imperial properties», Athenaeum, 54 (1976), pp. 19-36.

MARSHALL, A.J.: «Library resources and creative writing at Rome», Phoenix, xxx.3 (1976), pp. 252-264.

McKAY, A.G.: Houses, villas and palaces in the Roman World, Southampton, 1977.

PARKER, E.R.: «The education of heirs in the julio-claudian family», American Journal of Philology, 67 (1946), pp. 29-50.

PATERSON, J.R.: «The city of Rome: From republic to empire», Journal of Roman Studies, 82 (1992), pp. 186-215.

RICHARDSON, L.: «The evolution of the Porticus Octaviae», American Journal of Archaelogy, 80.1 (1976), pp. 57-64.

RODRIGUEZ VALCARCEL, JOSÉ A.: «Oderint dum metuant: el desarrollo del Gobierno de Cayo César en la ficción del principado». Madrid: FUE, 2004.

- «Procurator Bibliothecae Augusti: Los bibliotecarios del emperador en los inicios de las bibliotecas públicas en Roma», Anales de Documentación, 7 (2004), pp.231-239.

RODRIGUEZ VALCARCEL, JOSÉ A. ; FERNANDEZ URIEL, P.: «Julio César y la idea de biblioteca pública en la Roma antigua», Antigüedad y Cristianismo, XXIII (2006), pp.965979.

ROSTAGNI, A.: Storia della letteratura latina, II. Parte Prima: da Augusto a Nerone. Torino: Unione tipografica-Editrice Torinese, 1964. 
THORTON, M.K.: «Julio-Claudian building programs: eat, drink and be merry», Historia, 35 (1986), pp.28-44.

VAN BUREN, A.W.: «News letter from Rome», American Journal of Archaelogy, LXIII (1959), pp. 383-394.

VAN DEMAN, E.B.: “The house of Caligula», American Journal of Archaelogy, 28 (1924), pp. 368-398.

VIDAL, J.L.: «Por qué Virgilio quería quemar la Eneida...si es que quería», Humanitas. In honorem A. Fontán, Madrid: Gredos, 1992, pp. 479-484.

ZECCHINI, G.: «Asinio Pollione: dall'attività politica alla riflesione storiografica, $A N R W 2,30$, 2 (1982), pp. 1265-1296.

\section{TEXTOS}

Aulio Gelio, Noches Aticas.

Dión Casio, Historia romana.

Historia Augusta, vida de Tácito.

Horacio, Carmina.

Horacio, De arte poética.

Horacio, Epistuli.

Marcial, Epigrammaton.

Ovidio, Tristia.

Platón, La República, (Ed. Pabón, J.M.; Fernández Galiano, J.L.), Madrid, 1997.

Plinio, Cartas.

Plinio, Naturalis Historia.

Quintiliano, Institutiones oratoriae.

Séneca el viejo, Controversiae.

Séneca, Ad Marciam de Consolatione.

Séneca, De beneficiis.

Séneca, De clementia.

Séneca. De tranquillitate animi.

Suetonio, Vida de los doce césares: Augusto.

Suetonio, Vida de los doce césares: Calígula.

Suetonio, Vida de los doce césares: César.

Suetonio, Vida de los doce césares: Claudio.

Suetonio, De viris illustribus, vida de Virgilio.

Suetonio, Vida de los doce césares: Domiciano.

Suetonio, Vida de los doce césares: Tiberio.

Tácito, Agricola.

Tácito, Historias. 